\title{
53
}

\section{PRAIRIE GRASS}

\author{
I.R. Brown, J.G. Hampton and C. Lill
}

Prairie grass is used in dairy pastures and for winter/spring feed on sheep farms. Four. hundred and fifty-nine hectares of prairie grass were grown for seed in 1987/88. Average yields are $680 \mathrm{~kg} \mathrm{ha}^{-1}$; the specialist grower can achieve yields of $1400 \mathrm{~kg} \mathrm{ha}$.

\section{ESTABLISHMENT}

Site: Free-draining soils with medium fertility are suitable for prairie grass seed crops.

Paddock history: Prairie grass seed crops, like ryegrass, should be part of a rotation such as wheat, greenfeed, peas, barley, grass seed. This allows good weed control. Prairie grass for seed should not follow another grass seed crop and should not be sown into areas with known 'contamination with hair grass, goosegrass, yellow gromwell or twitch.

Time of sowing: Prairie grass can be sown in spring or autumn. No vernalisation period is required for production of seed. However, in general terms a crop sown sufficiently early in the autumn (end of February-early March) to be well-established by winter will yield better than one sown in the spring. This is because the plants in an autumn sown crop will be larger, and there will have been opportunity for grazing and weed control. Furthermore, a second harvest within the'season can be contemplated. Research has shown a direct relationship between earliness of sowing in the autumn and subsequent seed yield.

Seed-bed preparation: Seedling establishment can be enhanced by the preparation of a fine, firm, well-compacted, weed-free seed bed.

Sowing rate and depth: For seed crops $15-20 \mathrm{~kg} \mathrm{ha}^{-1}$ prairie grass seed should be drilled in $15 \mathrm{~cm}$ rows. If inter-row cultivation is required, $30 \mathrm{~cm}$ rows may be used without drastically reducing seed yield. Care must be taken not to bury the seed more than about $20 \mathrm{~mm}$.

Fertiliser: Autumn nittogen (30-40 units of $\mathrm{N} \mathrm{ha}^{-1}$ ) should be used if winter grazing is required. This nitrogen has no effect upon subsequent seed yield.

Weed and pest control: There are very few herbicides registered for use in seed crops. However, success in weed control has been achieved using chemicals registered for cereals once the seed crop has become established. Autumn/spring applications of herbicide may be required depending upon paddock history and winter grazing. MCPB at $1.2 \mathrm{~kg}$ a.i. ha-' has been used in spring with good effect.

In areas where grass grub is a problem, Dasanit should be applied at sowing. 
Disease control: Prairie grass is susceptible to head smut. Fungicide-treated seed should be sown in order to minimise the likelihood of attack.

\section{CROP MANAGEMENT}

Grazing: Autumn-sown crops may be grazed lightly during the winter if treated with nitrogen; but should be closed by the end of August. Spring-sown crops should not be grazed.

Fertiliser: Around 80 units of nitrogen applied just prior to stem elongation (i.e., when the first elongating stem can be felt) has proved beneficial to seed yield. Alternatively, 50 units can be applied in early August, and 50 units in midSeptember.

Irrigation:, Moisture stress reduces seed yield therefore water should be applied when necessary,

Fungicide; Prairie grass is prone to attack by anthracnose. Fungicides (e.g., Tilt) should be used to'prevent attack; curative measures are generally not successful. Application of fungicide at the end of September and mid-November (the fungicide is effective for four to six weeks) protects the crop for most of its susceptible period. Maintaining green leaf for, longer (research indicates lifespan is prolonged by $1-2$ weeks) due to absence of disease results in a significant increase in seed yield.

Growth regulators: Growth regulators such as cycocel (1 litre ha-'), PP333 and Terpal have been effective at reducing lodging in prairie grass. Cycocel and PP333 act as straw shorteners reducing bulk by up to $25 \%$; Terpal strengthens the straw. Seed yields may be increased with the use of growth regulators because of reduction in physical seed loss at harvest.

\section{HARVEST}

Time of harvest: Autumn-sown crops closed at the end of August can generally be harvested in the first fortnight in December. The second harvest should be possible by' the end of Februarv. Seed yields for the second harvest will be approximately half that of the first harvest (600-700 kgha" for a specialist grower).

Spring-sown crops are ready for harvest four to five months after sowing. No second harvest will be possible.

Crops should be cut when seed moisture is $42-45 \%$, and before it falls below $40 \%$ (when seed loss due to shattering of heads will occur).

Method of harvesting: Direct heading is the most efficient way of harvesting an unlodged crop. However, it is slow and seed must be dried artificially, which is expensive. 
Cutting with a sickle-bar mower and using lifters at harvest when the crop is around $14 \%$ moisture is recommended. The crop should be picked up as soon as possible because regrowth prairie grass can cause problems with lifting.

Once harvested, the seed should be allowed to cool either in drying silos or on drying floors. Seed brought in from the field can be at high temperatures and if stored immediately in bulk can heat, resulting in loss of viability. Seed is safe when cool and below $14 \%$ moisture.

Post-harvest treatment: Straw should-be baled and removed. As it is palatable it can be used for stock. If a second year crop is contemplated nitrogen should be applied, and no grazing should be allowed after the first of May.

\section{STAND LIFE}

Prairie grass stands can be certified for up to two years. However, because of the problems with head smut, second year crops are not recommended. 